\title{
Titanium Hydride Nanoplates Enable 5 wt\% of Reversible Hydrogen Storage by Sodium Alanate below $80^{\circ} \mathrm{C}$
}

\author{
Zhuanghe Ren, ${ }^{1}$ Xin Zhang, ${ }^{1}$ Hai-Wen Li, ${ }^{2}$ Zhenguo Huang, ${ }^{3}$ Jianjiang Hu $\mathbb{D},{ }^{4}$ \\ Mingxia Gao, ${ }^{1}$ Hongge Pan $\mathbb{D}^{1,5}$ and Yongfeng Liu ${ }^{1}{ }^{1,5}$ \\ ${ }^{1}$ State Key Laboratory of Silicon Materials and School of Materials Science and Engineering, Zhejiang University, \\ Hangzhou 310027, China \\ ${ }^{2}$ Hefei General Machinery Research Institute, Hefei 230031, China \\ ${ }^{3}$ School of Civil \& Environmental Engineering, University of Technology Sydney, 81 Broadway, Ultimo, NSW 2007, Australia \\ ${ }^{4}$ School of Chemistry and Chemical Engineering, Yantai University, Yantai 264005, China \\ ${ }^{5}$ Institute of Science and Technology for New Energy, Xi'an Technological University, Xi'an 710021, China
}

Correspondence should be addressed to Jianjiang Hu; jjj_hu@163.com, Hongge Pan; hgpan@zju.edu.cn, and Yongfeng Liu; mselyf@zju.edu.cn

Received 26 September 2021; Accepted 18 November 2021; Published 14 December 2021

\begin{abstract}
Copyright (c) 2021 Zhuanghe Ren et al. Exclusive Licensee Science and Technology Review Publishing House. Distributed under a Creative Commons Attribution License (CC BY 4.0).

Sodium alanate $\left(\mathrm{NaAlH}_{4}\right)$ with $5.6 \mathrm{wt} \%$ of hydrogen capacity suffers seriously from the sluggish kinetics for reversible hydrogen storage. Ti-based dopants such as $\mathrm{TiCl}_{4}, \mathrm{TiCl}_{3}, \mathrm{TiF}_{3}$, and $\mathrm{TiO}_{2}$ are prominent in enhancing the dehydrogenation kinetics and hence reducing the operation temperature. The tradeoff, however, is a considerable decrease of the reversible hydrogen capacity, which largely lowers the practical value of $\mathrm{NaAlH}_{4}$. Here, we successfully synthesized a new Ti-dopant, i.e., TiH $\mathrm{T}_{2}$ as nanoplates with $\sim 50 \mathrm{~nm}$ in lateral size and $\sim 15 \mathrm{~nm}$ in thickness by an ultrasound-driven metathesis reaction between $\mathrm{TiCl}_{4}$ and $\mathrm{LiH}$ in THF with graphene as supports (denoted as $\mathrm{NP}_{-} \mathrm{TiH}_{2} @ \mathrm{G}$ ). Doping of $7 \mathrm{wt} \% \mathrm{NP}-\mathrm{TiH}_{2} @ \mathrm{G}$ enables a full dehydrogenation of $\mathrm{NaAlH}_{4}$ at $80^{\circ} \mathrm{C}$ and rehydrogenation at $30^{\circ} \mathrm{C}$ under $100 \mathrm{~atm} \mathrm{H}_{2}$ with a reversible hydrogen capacity of $5 \mathrm{wt} \%$, superior to all literature results reported so far. This indicates that nanostructured $\mathrm{TiH}_{2}$ is much more effective than Tidopants in improving the hydrogen storage performance of $\mathrm{NaAlH}_{4}$. Our finding not only pushes the practical application of $\mathrm{NaAlH}_{4}$ forward greatly but also opens up new opportunities to tailor the kinetics with the minimal capacity loss.
\end{abstract}

\section{Introduction}

Hydrogen storage, bridging hydrogen generation and hydrogen application, plays a crucial role in a future hydrogen energy society [1-4]. Distinct from the matured technologies of compressed and liquefied hydrogen, solid state hydrides can realize higher hydrogen density under moderate pressures and temperature. Metal complex hydrides have attracted tremendous attention as the most promising hydrogen storage candidates because of their high gravimetric and volumetric hydrogen densities [5-8]. Sodium alanate, $\mathrm{NaAlH}_{4}$, is a typical complex hydride possessing $7.4 \mathrm{wt} \%$ of hydrogen capacity and favorable thermodynamics [9-12]. However, the sluggish kinetics results in high operation temperature and poor reversibility for hydrogen storage in $\mathrm{NaAlH}_{4}$, therefore limiting its practical on-board applications.

Catalyst doping has been proved a feasible approach to help reducing the kinetic barriers of hydrogen storage reactions in metal hydrides. Transition metals and their compounds, especially Ti-based dopants, were found to have the ability to promote fast dissociation and recombination of hydrogen molecules [12-14]. In this respect, Bogdanović and Schwickardi contributed an important breakthrough by introducing a few millimoles of $\mathrm{Ti}(\mathrm{OBu})_{4}$ or $\mathrm{TiCl}_{3}$ into $\mathrm{NaAlH}_{4}$, which enabled reversible hydrogen storage with $\mathrm{NaAlH}_{4}$ at moderate conditions [15]. After that, a variety of Ti-based species have been explored and evaluated, including halides, oxides, nitrides, borides, carbides, hydrides, alloys, and elemental metals (Figure 1) [16-31]. In most cases, the 


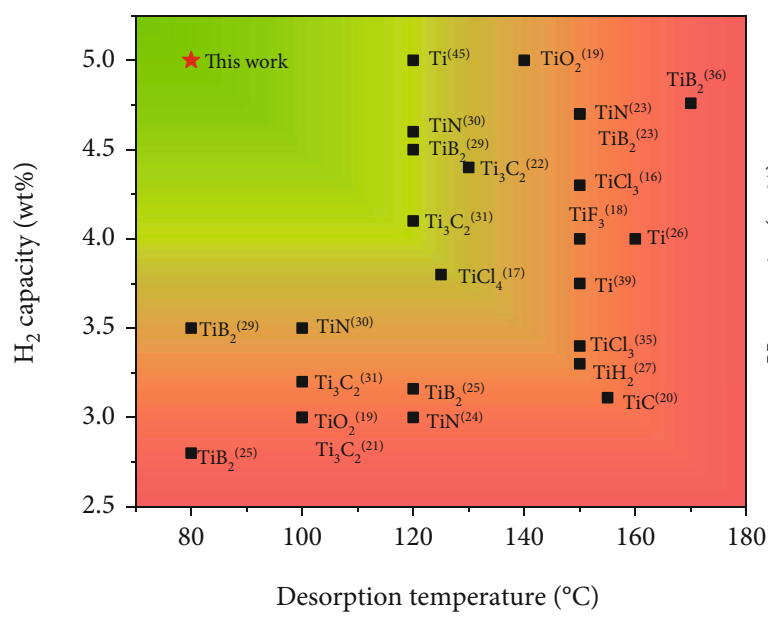

(a)

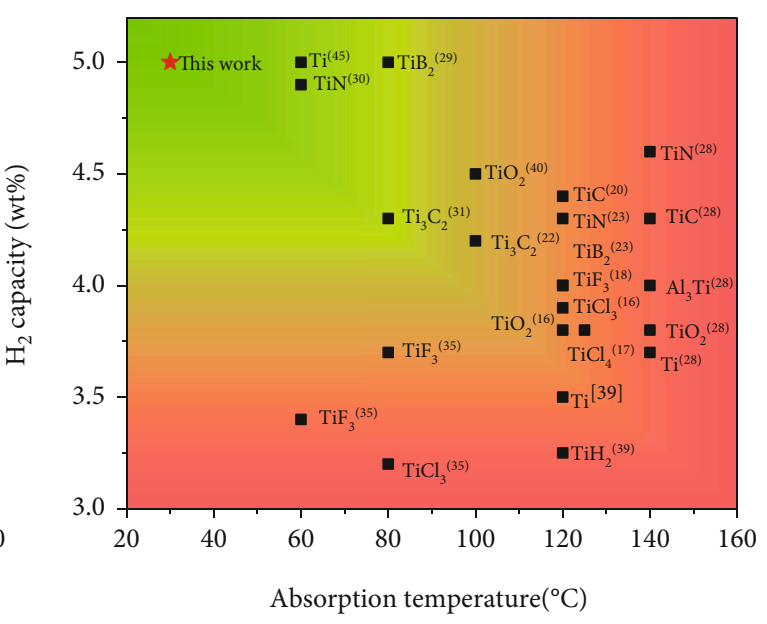

(b)

FIgURE 1: Comparison of hydrogen desorption (a) and absorption (b) performance of $\mathrm{NaAlH}_{4}$ doped with various Ti-based catalysts.

Ti-species tends to react with $\mathrm{NaAlH}_{4}$ to form $\mathrm{Ti}_{x} \mathrm{Al}_{y}$, which shows significant catalytic effect on the de-/rehydrogenation. Although most of the Ti-based species exhibit positive effects on the improvement of kinetics, the reduced hydrogen capacity becomes another important issue, especially for the heavy dopants [32]. More importantly, dopants with high valent $\mathrm{Ti}$ are readily reduced to the low valence and even to metal state of zero-valence during ball milling with $\mathrm{NaAlH}_{4}$, while the anions tend to combine with $\mathrm{Na}^{+}$to form hydrogen inert compounds, consequently further lowering the available hydrogen capacity of the whole composite $[16,33,34]$. As a result, the reversible hydrogen capacity remains only 3-4 wt\% for Ti-doped $\mathrm{NaAlH}_{4}$ system [35-37]. This is far from $5.6 \mathrm{wt} \%$ of theoretical value while $\mathrm{NaAlH}_{4}$ decomposes to $\mathrm{NaH}$ and $\mathrm{Al}$. Therefore, it is in great need to tackle the abovementioned trade-off issue between reaction temperature and hydrogen capacity of $\mathrm{NaAlH}_{4}$-based hydrogen storage materials.

Titanium hydride, $\mathrm{TiH}_{2}$, with Ti being already in low valent state and containing hydrogen itself, is expected to be a better candidate of dopant in comparison with other Ti-based compounds. More encouragingly, considerable studies show that the in situ formed $\mathrm{TiH}_{2}$ is a catalytic active phase in the Ti-based compound-modified $\mathrm{NaAlH}_{4}$ systems [38-43]. For example, Gross et al. observed the conversion of $\mathrm{NaH} / \mathrm{Al}$ to $\mathrm{NaAlH}_{4}$ at $130^{\circ} \mathrm{C}$ and $82 \mathrm{~atm} \mathrm{H}_{2}$ with the presence of $\mathrm{TiH}_{2}$, indicating a remarkable improvement of hydrogenation properties [38]. Kang et al. reported the in situ generation of $\mathrm{TiH}_{2}$ after mechanical milling of metallic Ti powder with $\mathrm{NaH} / \mathrm{Al}$ mixture under $\mathrm{H}_{2}$ atmosphere [39]. A similar phenomenon was also observed during hydrogenation of the $\mathrm{TiO}_{2}$-modified $\mathrm{NaAlH}_{4}$ system [40]. Moreover, theoretical predications supported the creation of $\mathrm{Ti}-\mathrm{H}$ bonds via extracting hydrogen atoms from the accessible $\mathrm{AlH}_{4} / \mathrm{AlH}_{3}$ groups [41-43]. However, introduction of commercial $\mathrm{TiH}_{2}$ into $\mathrm{NaAlH}_{4}$ seemed not very effective (only releasing $3.3 \mathrm{wt} \% \mathrm{H}_{2}$ within $10 \mathrm{~h}$ at $150^{\circ} \mathrm{C}$ ), which may be due to the large $\mathrm{TiH}_{2}$ particle, and thus, the catalytic interactions between $\mathrm{TiH}_{2}$ and $\mathrm{NaAlH}_{4}$ were limited [27]. It is therefore an open question to trigger the high catalytic activity of $\mathrm{TiH}_{2}$ that would reduce the reaction temperature and keep a high hydrogen capacity of $\mathrm{NaAlH}_{4}$ simultaneously.

In this work, we develop a novel facile sonochemical process for the fabrication of two-dimensional (2D) $\mathrm{TiH}_{2}$ nanoplates. Ultrasound was used to drive the formation of nanometer $\mathrm{TiH}_{2}$ on graphene by reacting $\mathrm{TiCl}_{4}$ with $\mathrm{LiH}$ in THF solution, thanks to the high solubility of $\mathrm{LiCl}$. Well-defined $\mathrm{TiH}_{2}$ nanoplates with a lateral size of $\sim 50 \mathrm{~nm}$ and thickness of $\sim 15 \mathrm{~nm}$ on graphene (denoted as NP$\left.\mathrm{TiH}_{2} @ \mathrm{G}\right)$ were successfully obtained. Outstanding catalytic activity for hydrogen storage reaction of $\mathrm{NaAlH}_{4}$ was found to be related to the significantly enhanced surface area and excellent dispersibility in comparison with commercial $\mathrm{TiH}_{2}$ in microscale. Full dehydrogenation and rehydrogenation were achieved, respectively, at $80^{\circ} \mathrm{C}$ and $30^{\circ} \mathrm{C}$, with a practical capacity of $5 \mathrm{wt} \%$ for $\mathrm{NaAlH}_{4}$ doped with $7 \mathrm{wt} \%$ NP-TiH ${ }_{2} @ \mathrm{G}$. To the best of our knowledge, this is the first example that $\mathrm{NaAlH}_{4}$ can reversibly store hydrogen in the working temperature range of proton exchange membrane fuel cell (PEMFC) with the highest capacity (Figure 1). Such outstanding hydrogen storage performance of $\mathrm{NaAlH}_{4}$ meets the requirement for on-board hydrogen storage application.

\section{Results}

2.1. Preparation of $\mathrm{TiH}_{2}$ Nanoplates. The process for the preparation of $\mathrm{TiH}_{2}$ nanoplates was developed, as illustrated schematically in Figure 2, based on the following chemical reaction.

$$
\mathrm{TiCl}_{4}+4 \mathrm{LiH} \underset{\text { Ultrasonification }}{\stackrel{\mathrm{THF}}{\longrightarrow}} \mathrm{TiH}_{2}+4 \mathrm{LiCl}+\mathrm{H}_{2} \uparrow
$$

All sample handling was conducted in an Ar-filled glove box. Firstly, stoichiometric titanium tetrachloride $\left(\mathrm{TiCl}_{4}\right)$ 


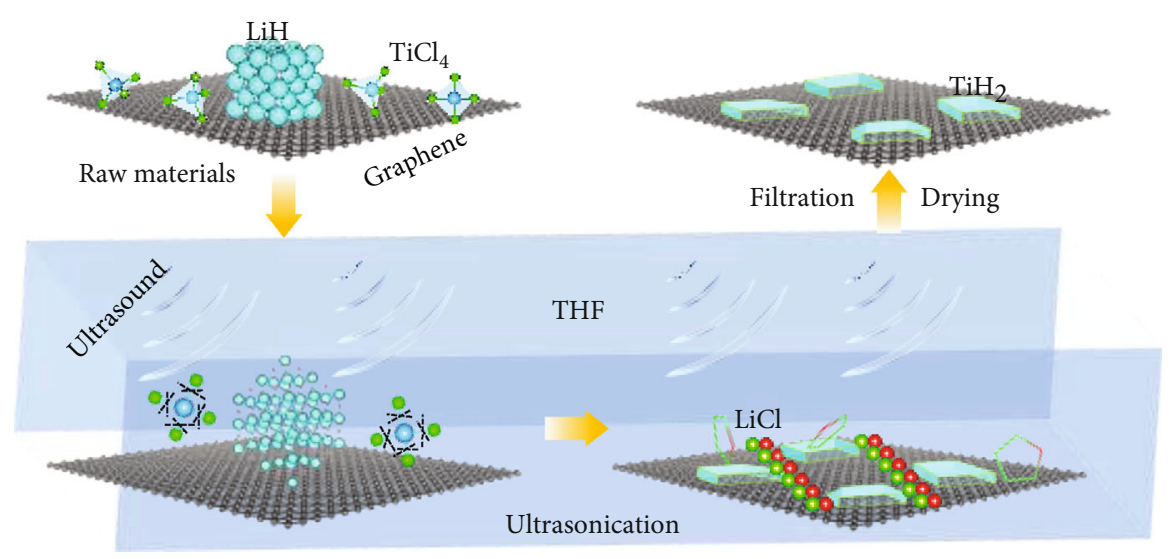

Figure 2: Schematic illustration for the preparation process of $\mathrm{TiH}_{2}$ nanoplates.

and lithium hydride ( $\mathrm{LiH})$ along with a certain amount of graphene were added to tetrahydrofuran (THF) solution. Subsequently, the sonochemical process was conducted for $4 \mathrm{~h}$ at $40 \mathrm{kHz}$ with continuous stirring. Finally, the solidstate product was obtained after filtrating, washing, and drying.

Only a broad diffraction peak at around $25^{\circ}$ with high background was observed in the X-ray diffraction (XRD) profile (Figure 3(a)), suggesting that the solid-state product was in amorphous or nanocrystalline state. Energy dispersive spectroscopy (EDS) analysis revealed that it was mainly composed of $\mathrm{Ti}$ and $\mathrm{C}$ in addition to a traced amount of $\mathrm{Cl}$ and $\mathrm{O}$ as impurities (Figure 3(b)). Further Raman characterization indicated that the $\mathrm{C}$ signal could reasonably be attributed to graphene from the characteristic D-band and G-band at 1340 and $1590 \mathrm{~cm}^{-1}$, respectively (Figure S1, Supporting Information). More importantly, $\mathrm{H}_{2}$ emission was detected by mass spectroscopy (MS) while heating the solid-state product (Figure 3(c)). A sample in the absence of graphene was prepared according to reaction (1) with the same process to determine exactly the $\mathrm{H}$ content. Thermogravimetric analysis (TGA) results indicated around $4 \mathrm{wt} \%$ of weight loss (Figure $3(\mathrm{~d})$ ), agreeing well with the $\mathrm{H}$ content in $\mathrm{TiH}_{2}$. It is worth noting that the peak temperature for the hydrogen release of the solid product is around $120^{\circ} \mathrm{C}$ (Figure $3(\mathrm{c})$ ), much lower than that of $\mathrm{TiH}_{2}$ in microscale $\left(>500^{\circ} \mathrm{C}\right)$ [44]. Suggesting the successful synthesis of nanosized $\mathrm{TiH}_{2}$. Furthermore, the generation of $\mathrm{H}_{2}$ as a gaseous product (Figure S2, Supporting Information) and the formation of $\mathrm{LiCl}$ in the filtrate (Figure S3, Supporting Information) as byproducts of reaction (1) were confirmed in the sonochemical process. Thus, the resultant solid-state product consisted of nanosized $\mathrm{TiH}_{2}$ and graphene.

Figure 4 shows the morphology of the prepared $\mathrm{TiH}_{2}$. As shown in Figure 4(a), a large number of black nanoplates with $\sim 50 \mathrm{~nm}$ of average size dispersed on graphene can be observed from the transmission electron microscope (TEM) image. EDS mapping indicated that these nanoplates were mainly composed of $\mathrm{Ti}$ and $\mathrm{C}$ elements (Figure 4(b)). High-resolution TEM (HRTEM) clearly presents the fringes of interplanar spacing of $0.21 \mathrm{~nm}$ (Figure 4(c)), which corresponds to the (002) planes of $\mathrm{TiH}_{2}$. The TEM observations, therefore, strongly prove the successful synthesis of graphene-supported $\mathrm{TiH}_{2}$ nanoplates (denoted as NP$\mathrm{TiH}_{2} @ \mathrm{G}$ hereinafter) by a newly developed sonochemical process. The thickness of the prepared $\mathrm{TiH}_{2}$ nanoplates was determined as $\sim 15 \mathrm{~nm}$ by atomic force microscope (AFM) measurement (Figure 4(d)).

A time dependence of growth of $\mathrm{TiH}_{2}$ nanoplates was also clearly observed by means of TEM (as shown in Figure 5). For comparison, the pristine graphene with a clean surface is shown in Figure S4 (Supporting Information). After $1 \mathrm{~h}$ of ultrasonic treatment, a large number of $\sim 10 \mathrm{~nm}$ sized black sheets cover on the graphene (Figures 5(a) and 5(b)). Extending the time to $2 \mathrm{~h}$, some nanoplates grew up to $\sim 50 \mathrm{~nm}$ (Figures 5(c) and 5(d)). Further extending to $4 \mathrm{~h}$, the $\sim 50 \mathrm{~nm}$-sized nanoplates were largely increased in quantity along with the disappearance of small nanosheets (Figures 5(e) and 5(f)). The loading amount of $\mathrm{TiH}_{2}$ was determined to be $\sim 70 \%$ in weight by inductively coupled plasma spectroscopy (ICP) examination, which is distinctly higher than that obtained previously by a solvothermal process ( 46\%) [44]. Thus, higher catalytic activity was expected. In a strong contrast, only coarse particles with $\sim 500 \mathrm{~nm}$ in size were obtained via the same sonochemical process without graphene as support (Figure S5, Supporting Information). This fact unambiguously indicates the critical important role played by graphene as a hard template governing the morphology of $\mathrm{TiH}_{2}$ nanoplate, attributed to the very similarity in lattice spacings $(2.10 \AA$ for the (002) planes of $\mathrm{TiH}_{2}$ and $2.13 \AA$ for the (100) planes of graphene) [44].

2.2. Catalytic Activity of $\mathrm{TiH}_{2}$ Nanoplates. The $4 \mathrm{~h}$-sonicated $\mathrm{NP}-\mathrm{TiH}_{2} @ \mathrm{G}$ was selected to mix with $\mathrm{NaAlH}_{4}$ by ball milling in order to evaluate its catalytic effectiveness because it took $4 \mathrm{~h}$ to complete the conversion of $\mathrm{TiH}_{2}$ from $\mathrm{TiCl}_{4}$ as indicated by the thorough disappearance of the characteristic reflections of $\mathrm{LiH}$ in the XRD profile after $4 \mathrm{~h}$ of sonification (Figure S6, Supporting Information). Six samples of 


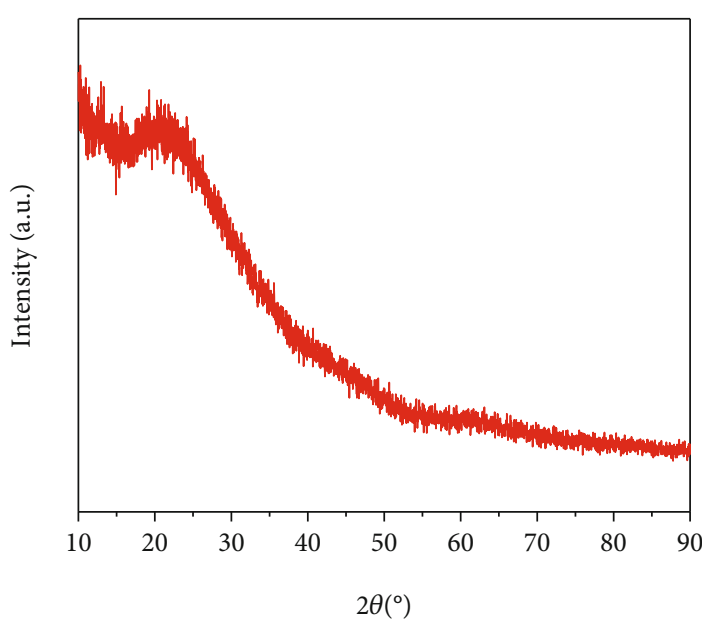

(a)

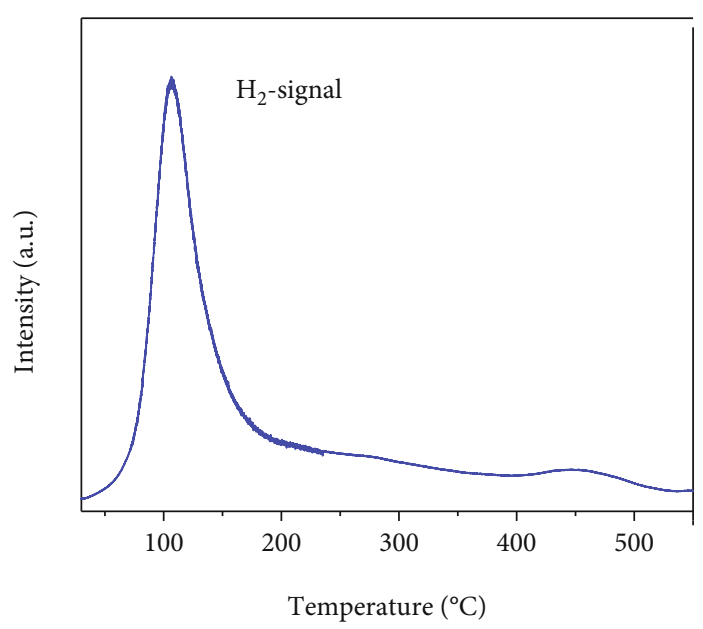

(c)

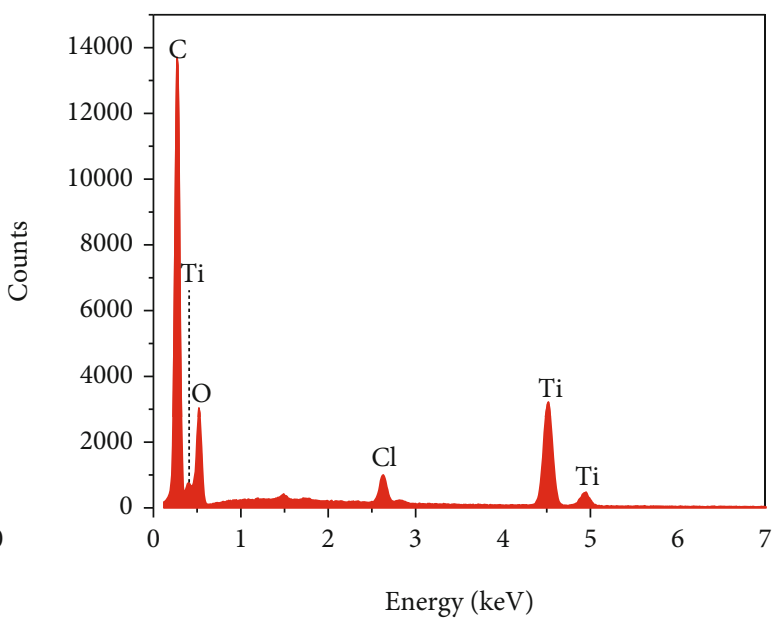

(b)

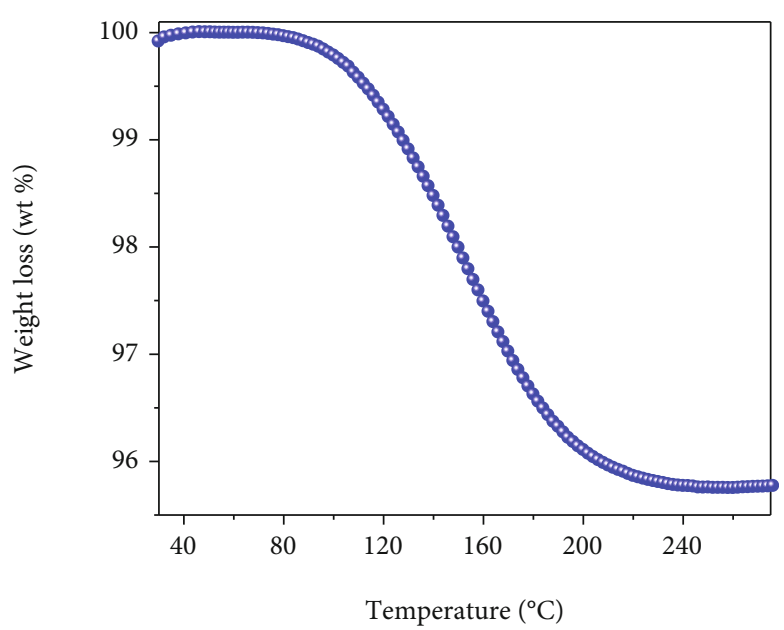

(d)

FIGURE 3: (a) XRD pattern, (b) EDS spectrum, (c) TPD-MS signal, and (d) TGA curve of as-prepared solid products of the sonochemical reaction between $\mathrm{TiCl}_{4}$ and $\mathrm{LiH}$ in THF.

$\mathrm{NaAlH}_{4}-x \mathrm{NP}-\mathrm{TiH}_{2} @ \mathrm{G}$ with $x=0,1,3,5,7$, and 9 wt\% were examined. A remarkable reduction in the dehydrogenation temperature of $\mathrm{NaAlH}_{4}$ was observed as $\mathrm{NP}-\mathrm{TiH}_{2} @ \mathrm{G}$ increasing from $1 \mathrm{wt} \%$ to $7 \mathrm{wt} \%$ (as shown in Figure 6(a)). For the $7 \mathrm{wt} \% \mathrm{NP}-\mathrm{TiH}_{2} @ \mathrm{G}$-containing sample, the release of hydrogen started from $80^{\circ} \mathrm{C}$ and completed at $160^{\circ} \mathrm{C}$ with an usable hydrogen capacity of $5 \mathrm{wt} \%$. The on-set and end temperatures of dehydrogenation were reduced by 115 and $180^{\circ} \mathrm{C}$, respectively, compared to those of the pristine $\mathrm{NaAlH}_{4}$. Further increase of NP-TiH ${ }_{2} @ \mathrm{G}$ to $9 \mathrm{wt} \%$ caused an obvious loss of hydrogen capacity without obvious reduction in the dehydrogenation temperature. Therefore, 7 wt\% was the optimal amount for $\mathrm{NP}-\mathrm{TiH}_{2} @ \mathrm{G}$ by taking into account of the hydrogen capacity and the dehydrogenation temperature.

The dehydrogenated sample was subsequently subjected to hydrogenation with ramped temperatures under $100 \mathrm{~atm}$ of $\mathrm{H}_{2}$ pressure (as shown in Figure 6(b)). The $7 \mathrm{wt} \%$ NP$\mathrm{TiH}_{2} @ \mathrm{G}$-containg sample showed superior rehydrogenation properties to those of pristine $\mathrm{NaAlH}_{4}$ and $\mathrm{NaAlH}_{4}$ doped with the commercial $\mathrm{TiH}_{2}$. Specifically, $7 \mathrm{wt} \%$ NP$\mathrm{TiH}_{2} @ \mathrm{G}$-containg sample absorbed $5 \mathrm{wt} \% \mathrm{H}_{2}$ from $25^{\circ} \mathrm{C}$ to $105^{\circ} \mathrm{C}$. It is worth emphasizing that the $7 \mathrm{wt} \% \mathrm{NP}$ $\mathrm{TiH}_{2} @ \mathrm{G}$-containing sample started to absorb hydrogen at a temperature as low as $25^{\circ} \mathrm{C}$, and more than $90 \%$ of the rehydrogenation can be completed below $90^{\circ} \mathrm{C}$, which is close to the working temperature of PEMFC. Such significant improvement of the rehydrogenation by the addition

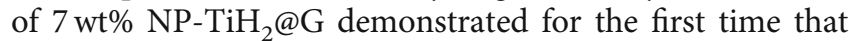
high reversible capacity coupled with the dehydrogenation temperature of $\mathrm{NaAlH}_{4}$ can be achieved simultaneously by a proper dopant, which can be mainly attributed to the highly homogenous dispersion of the prepared NP-TiH $\mathrm{T}_{2} @ \mathrm{G}$ (Figure 6(c)) than that of the commercial $\mathrm{TiH}_{2}$ (Figure 6(d)) in $\mathrm{NaAlH}_{4}$. The Ti-rich area was clearly observed in $\mathrm{NaAlH}_{4}$ doped with the commercial $\mathrm{TiH}_{2}$, probably due to the large particle size of $\mathrm{TiH}_{2}$ (Figure S7, Supporting Information). More importantly, most of the $\mathrm{NP}-\mathrm{TiH}_{2}$ was converted to 


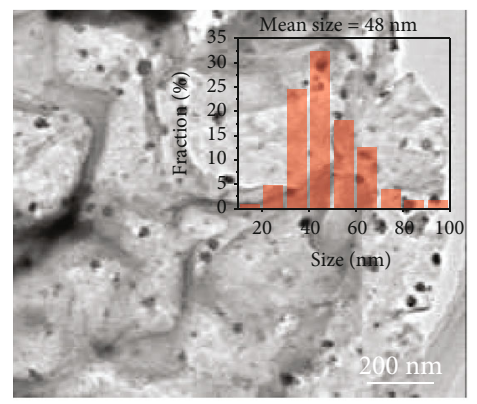

(a)

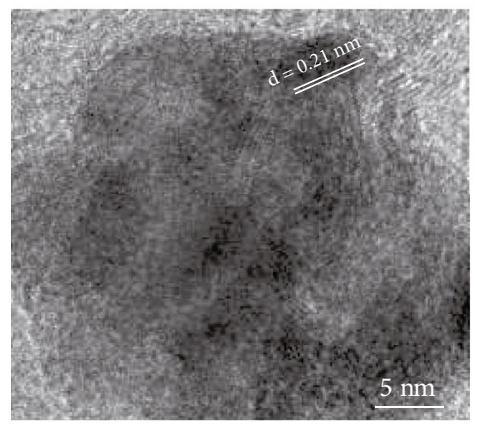

(c)

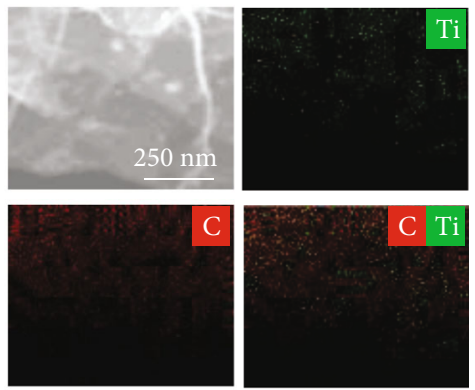

(b)

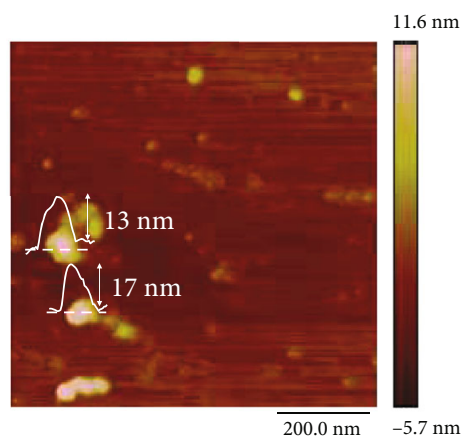

(d)

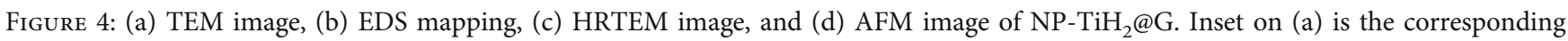
particle size distribution.

Al-Ti species after $24 \mathrm{~h}$ ball milling with $\mathrm{NaAlH}_{4}$, whereas only small amount of Al-Ti species can be detected in the commercial $\mathrm{TiH}_{2}$ (Figure S8, Supporting Information). This suggests that the reduced particle size of $\mathrm{TiH}_{2}$ facilitates the formation of Al-Ti species, which possess high catalytic activity for the dehydrogenation and rehydrogenation of $\mathrm{NaAlH}_{4}[9,34,40]$. Further XRD characterization indicated that the reversible hydrogen capacity still originated from the decomposition and reformation of $\mathrm{NaAlH}_{4}$ (as shown in Figure S9 (Supporting Information)).

Moreover, the dehydrogenation temperature was further reduced by $\sim 10^{\circ} \mathrm{C}$ in the follow-up 2nd cycle (Figure S10, Supporting Information). It can be clearly seen that the particle size of Ti-containing species reduced largely to around $5 \mathrm{~nm}$ from the aberration-corrected scanning transmission electron microscope (STEM) observation and EDS mapping analyses (as shown in Figure 7). From the relative content analyses, the $\mathrm{Al}-\mathrm{Ti}$ species changed from $\mathrm{Al}_{85} \mathrm{Ti}_{15}$ for the as-milled sample to $\mathrm{Al}_{58} \mathrm{Ti}_{42}$ for the cycled sample, close to $\mathrm{Al}_{50} \mathrm{Ti}_{50}$, suggesting the reconstruction or optimization of the local atomic structure of Al-Ti species during cycling. This is further evidenced by the slight lowangle shift of the characteristic reflection of Al-Ti species in the XRD profiles because of the incorporation of more $\mathrm{Ti}$ (Figure S11, Supporting Information). According to the density functional theory (DFT) calculation, the kinetic barrier of the transfer of $\mathrm{H}$ atom from $\mathrm{NaAlH}_{4}$ to the surface of $\mathrm{Al}$ is largely reduced from $0.47 \mathrm{eV}$ (Figure S12a,
Supporting Information) to $0.14 \mathrm{eV}$ (Figure S12b, Supporting Information) with the present of one $\mathrm{Ti}$ atom. This process can even proceed spontaneously when two $\mathrm{Ti}$ atoms are introduced into the surface of $\mathrm{Al}$ in the near-nearestneighbor mode (Figure S12c, Supporting Information). This suggests that the Al-Ti species are of great importance for the significant improvement of dehydrogenation kinetics of $\mathrm{NaAlH}_{4}$, which agrees well with the previous reports [40, 45].

\subsection{Hydrogen Storage Kinetics of NP-TiH $\mathrm{H}_{2} @ G$-Containing} $\mathrm{NaAlH}_{4}$. Figures 8(a) and 8(b) show the isothermal dehydrogenation behaviors of $\mathrm{NaAlH}_{4}-7 \mathrm{wt} \% \mathrm{NP}-\mathrm{TiH}_{2} @ \mathrm{G}$ sample after 1 dehydrogenation/rehydrogenation cycle, measured by volumetric and thermogravimetric (TG) methods, respectively. Isothermal volumetric dehydrogenation indicates that the full dehydrogenation of $5 \mathrm{wt} \%$ of hydrogen was achieved within $30 \mathrm{~min}$ at $140^{\circ} \mathrm{C}$. At $120^{\circ} \mathrm{C}$, it took around $200 \mathrm{~min}$ to complete. Even at $100^{\circ} \mathrm{C}$, the major part of hydrogen (around 3.2 wt\%) can be released within $30 \mathrm{~min}$ and the dehydrogenation completed within $500 \mathrm{~min}$. The time for the full dehydrogenation was reduced to only $250 \mathrm{~min}$ at TG measurement (Figure $8(\mathrm{~b})$ ), which is attributed to the absence of blocking effect from hydrogen back pressure. More encouragingly, the full dehydrogenation can be achieved even at $80^{\circ} \mathrm{C}$, which is the lowest dehydrogenation temperature for $\mathrm{NaAlH}_{4}$ reported so far.

The full isothermal rehydrogenation $(\sim 5 \mathrm{wt} \%$ of hydrogen) of dehydrogenated $\mathrm{NaAlH}_{4}-7 \mathrm{wt} \% \mathrm{NP}-\mathrm{TiH}_{2} @ \mathrm{G}$ completed within only $25 \mathrm{~min}$ at $100^{\circ} \mathrm{C}$ (as shown in 


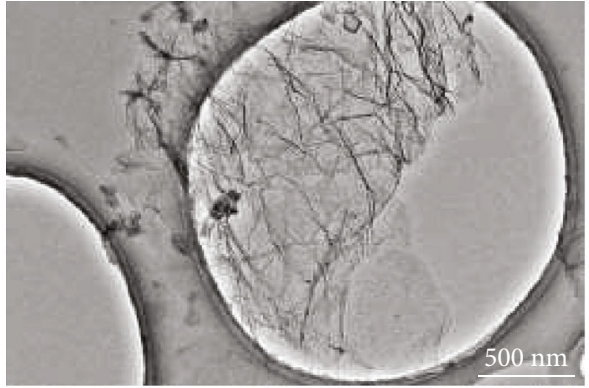

(a)

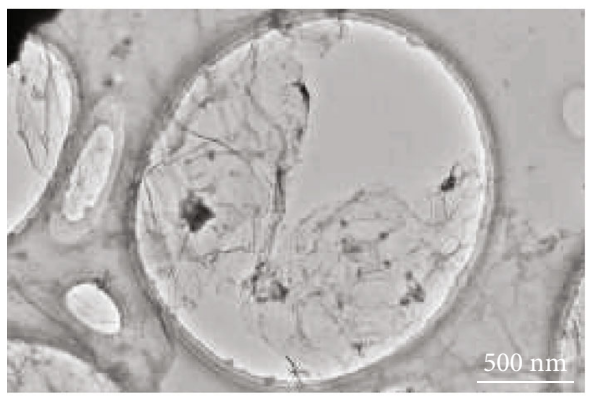

(c)

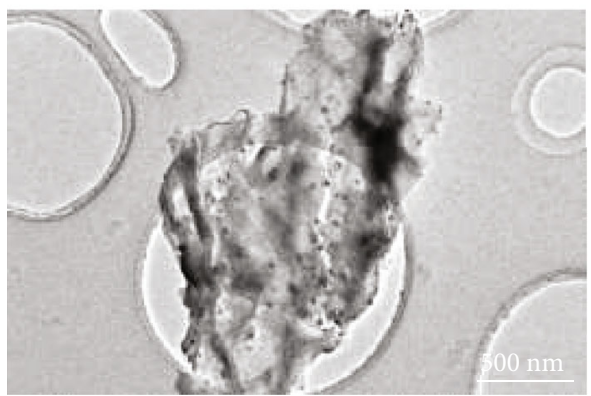

(e)

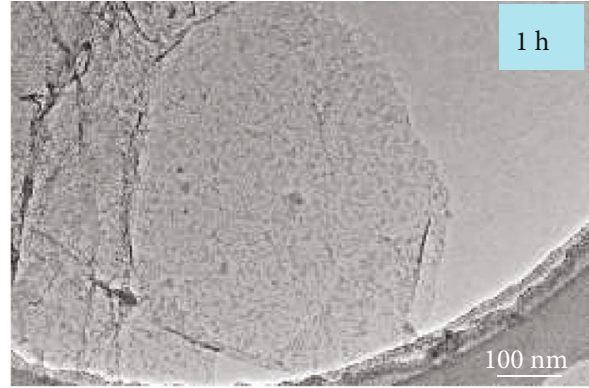

(b)

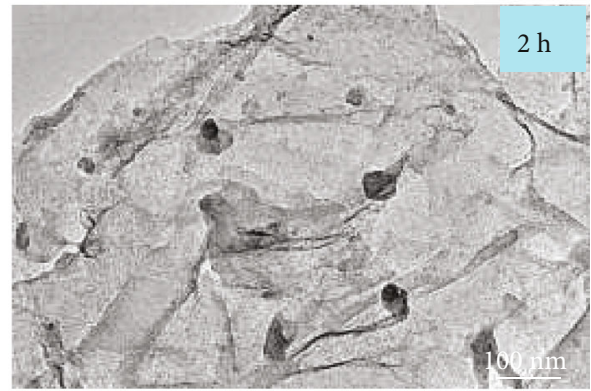

(d)

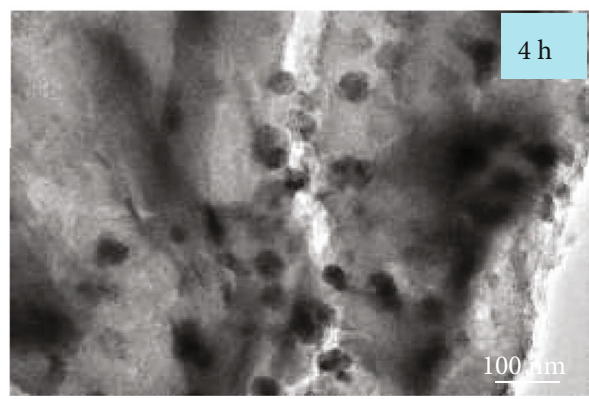

(f)

Figure 5: TEM images of NP-TiH $@$ @G with the ultrasonic time of $1 \mathrm{~h}(\mathrm{a}, \mathrm{b}), 2 \mathrm{~h}(\mathrm{c}, \mathrm{d})$, and $4 \mathrm{~h}(\mathrm{e}, \mathrm{f})$.

Figure 8(c)). Amazingly, the full rehydrogenation was also achieved even at $30^{\circ} \mathrm{C}$. This is the first complex hydride system that is able to work at the target temperature range proposed by US DOE with $5 \mathrm{wt} \%$ of reversible hydrogen capacity, although the dehydrogenation/rehydrogenation rates need to be further improved [46].

The apparent activation energy of dehydrogenation reactions of $\mathrm{NaAlH}_{4}-7 \mathrm{wt} \% \mathrm{NP}-\mathrm{TiH}_{2} @ \mathrm{G}$ was calculated based on the Kissinger's plots (Figure 8(d)), in which the peak temperatures and the heating rates were obtained from temperature programmed desorption (TPD) curves shown in Figure S13 (Supporting Information). The apparent activation energies for each step are $80 \pm 3.3$ and $70 \pm 2.8$ $\mathrm{kJ} \mathrm{mol}^{-1}$, respectively. These values are reduced by $\sim 40 \%$ compared to those of the pristine $\mathrm{NaAlH}_{4}$ [47], and even remarkably lower than those of other catalyst-modified $\mathrm{NaAlH}_{4}$ systems (Table S1) [48-54], indicating the significant reduction of the dehydrogenation kinetic barriers induced by the newly formed $\mathrm{Al}-\mathrm{Ti}$ catalytic species. In contrast, the addition of $7 \mathrm{wt} \% \mathrm{NP}-\mathrm{TiH}_{2} @ \mathrm{G}$ did not affect much the thermodynamic properties of $\mathrm{NaAlH}_{4}$ as indicated by the nearly unchanged desorption enthalpy change, which were determined to be approximately $36.5 /$ 47.4 and $36.3 / 47.0 \mathrm{~kJ} / \mathrm{mol}-\mathrm{H}_{2}$ for pristine sample and $7 \mathrm{wt} \%$ $\mathrm{NP}-\mathrm{TiH}_{2} @ \mathrm{G}$-containing sample, respectively, by analyzing the differential scanning calorimetry (DSC) results (Figure S14, Supporting Information).

2.4. Dehydrogenation/Rehydrogenation Cycling of NP$\mathrm{TiH}_{2} @ G$-Containing $\mathrm{NaAlH}_{4}$. Dehydrogenation/rehydrogenation cycling performance of the $\mathrm{NaAlH}_{4}-7 \mathrm{wt} \%$ NP$\mathrm{TiH}_{2} @ \mathrm{G}$ sample is shown in Figure 9(a). Here, dehydrogenation was operated at $140^{\circ} \mathrm{C}$ under initial vacuum and rehydrogenation at $100^{\circ} \mathrm{C} / 100 \mathrm{~atm} \mathrm{H}_{2}$. No obvious degradation was observed after 50 cycles. The hydrogen capacity was $4.8 \mathrm{wt} \%$ at the 50th cycle, which means a capacity retention 


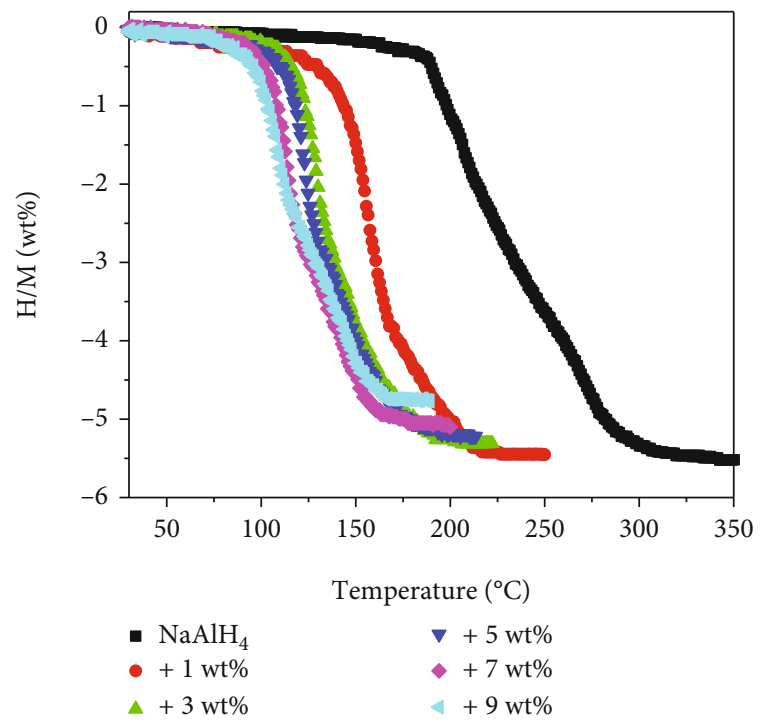

(a)
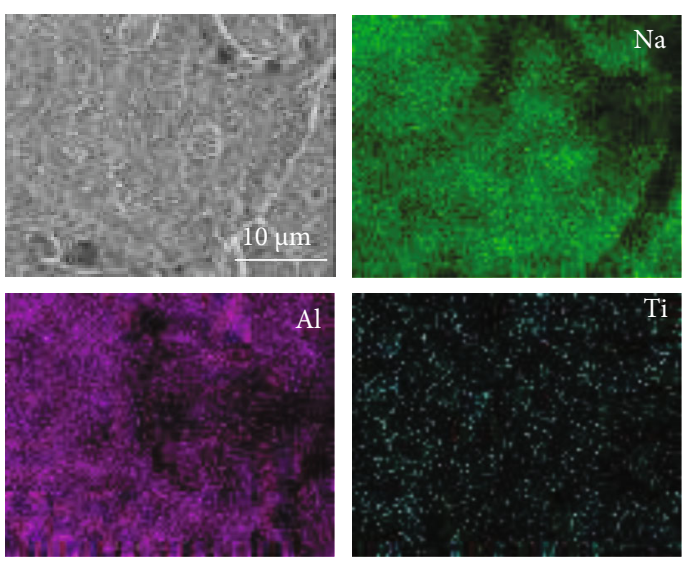

(c)

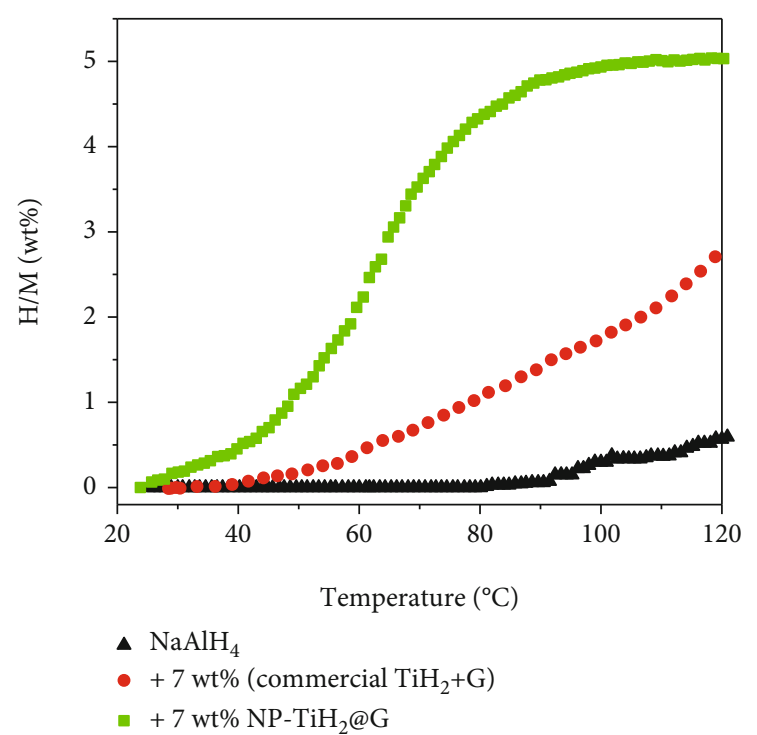

(b)
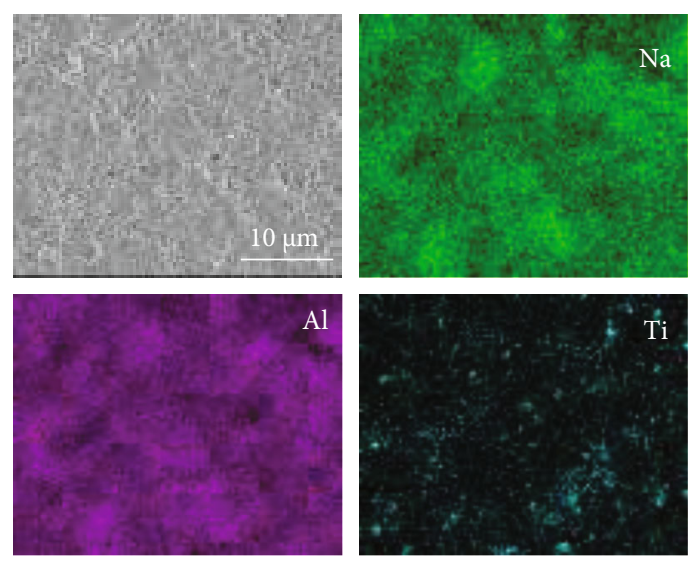

(d)

FIgURE 6: (a) Volumetric release curves of $\mathrm{NaAlH}_{4}$ doped with $\mathrm{NP}-\mathrm{TiH}_{2} @ \mathrm{G}$, (b) nonisothermal hydrogenation curves, and (c, d) SEM and corresponding EDS mapping of $\mathrm{NaAlH}_{4}$ mixed with $7 \mathrm{wt} \%$ (c) $\mathrm{TiH}_{2}$ nanoplates and (d) commercial $\mathrm{TiH}_{2}$.

of $96 \%$ based on the initial capacity of $5.0 \mathrm{wt} \%$. The cycling performance demonstrates a stable cyclability of the NP$\mathrm{TiH}_{2} @$ G-containing $\mathrm{NaAlH}_{4}$.

To shed light on the stable cycling behavior of NP$\mathrm{TiH}_{2} @ \mathrm{G}$-containing $\mathrm{NaAlH}_{4}$, the particle size, distribution, and chemical states of catalytic species were examined and analyzed. TEM observation displayed that the catalytic species remained as ultrafine particles of $\sim 5 \mathrm{~nm}$ in size without obvious agglomeration (Figure 9(b)). EDS mapping analyses (Figures 9(c) and 9(d)) indicated the homogenous distribution of Ti element on $\mathrm{NaAlH}_{4}$ matrix even after 50 cycles. In addition, high-resolution XPS spectra of Ti $2 \mathrm{p}$ showed a stable chemical state from 2 to 50 cycles for the nearly unchanged $2 \mathrm{p}_{3 / 2}-2 \mathrm{p}_{1 / 2}$ spin-orbit doublet at $453.2 / 458.1 \mathrm{eV}$ (Figure 9(e)) [55]. As a result, we believe that the small particle size, homogenous dispersion, and stable chemical state are of critical importance for the long-term cyclability of $\mathrm{NP}-\mathrm{TiH}_{2} @ \mathrm{G}$-containing $\mathrm{NaAlH}_{4}$. This finding provides important insights and greatly encourages the further devel- opment of the catalysis-promoted complex hydrides for practical on-board applications.

\section{Discussion}

Two-dimensional $\mathrm{TiH}_{2}$ nanoplates with a lateral size of $50 \mathrm{~nm}$ and a thickness of $15 \mathrm{~nm}$ were successfully synthesized by using graphene as support, based on a novel facile sonochemical process. The graphene played a critical role in the nucleation and growth of $\mathrm{TiH}_{2}$ nanoplates. The prepared $\mathrm{TiH}_{2}$ nanoplates displayed superior catalytic activity than the commercial $\mathrm{TiH}_{2}$ of microscale for hydrogen storage in $\mathrm{NaAlH}_{4}$. The $7 \mathrm{wt} \% \mathrm{NP}-\mathrm{TiH}_{2} @ \mathrm{G}$-containing $\mathrm{NaAlH}_{4}$ started releasing hydrogen at $80^{\circ} \mathrm{C}$, which was lowered by $115^{\circ} \mathrm{C}$ in comparison with pristine sample. In TG measurement, full dehydrogenation was achieved with $5.0 \mathrm{wt} \%$ of practical hydrogen capacity even at $80^{\circ} \mathrm{C}$. It is worth emphasizing that the rehydrogenation can complete at $30^{\circ} \mathrm{C}$ under $100 \mathrm{~atm}$ of $\mathrm{H}_{2}$. Operating at $140^{\circ} \mathrm{C} /$ initial vacuum for 

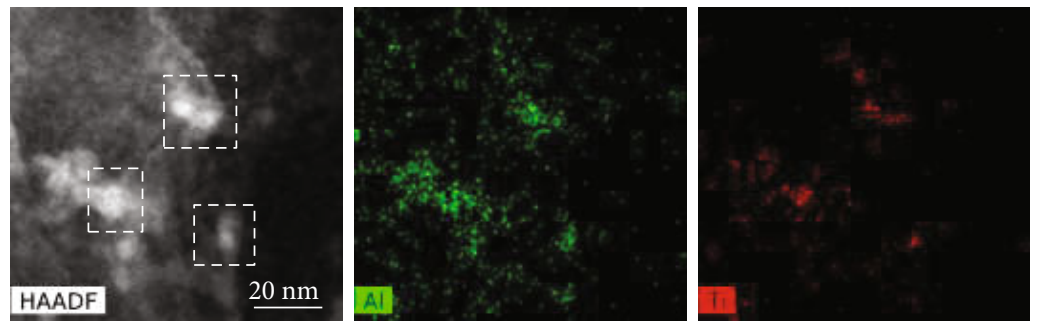

(a)
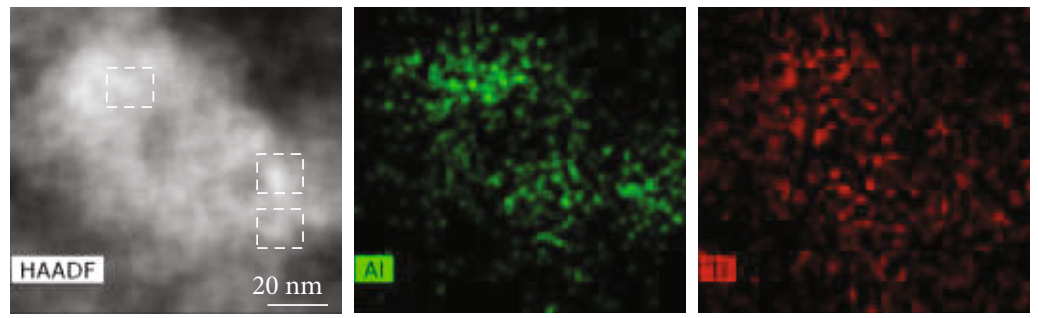

(b)

FIGURE 7: STEM and corresponding EDS mapping of as-milled (a) and activated (b) $\mathrm{NaAlH}_{4}-7$ wt\% NP-TiH $\mathrm{N}_{2} @ \mathrm{G}$ samples. The rectangular areas in (a) and (b) are taken for composition analysis.

dehydrogenation and $100^{\circ} \mathrm{C} / 100 \mathrm{~atm} \mathrm{H}_{2}$ for rehydrogenation, a stable cyclability was confirmed, as only $0.2 \mathrm{wt} \%$ of capacity loss after 50 cycles. Mechanistic studies revealed the active catalytic species was converted from $\mathrm{TiH}_{2}$ to $\mathrm{Al}_{85} \mathrm{Ti}_{15}$ during ball milling and further to near $\mathrm{Al}_{50} \mathrm{Ti}_{50}$ after the first de-/hydrogenation cycle, which remained stable in the subsequent cycling. DFT calculations reveal that the kinetic barrier of the transfer of $\mathrm{H}$ atom from $\mathrm{NaAlH}_{4}$ to the surface of $\mathrm{Al}$ is largely reduced by the formation of Al-Ti species. The small particle, homogenous dispersion and stable chemical state of active catalytic species are responsible for the long-term cyclability of NP-TiH ${ }_{2} @ G-$ containing $\mathrm{NaAlH}_{4}$. The findings presented in this work make $\mathrm{NaAlH}_{4}$ step closer towards practical on-board hydrogen storage applications.

\section{Materials and Methods}

4.1. Materials Synthesis. All reagents and solvents were purchased and used as received without further purification. $\mathrm{TiH}_{2}$ nanoplates supported on graphene (NP- $\left.\mathrm{TiH}_{2} @ \mathrm{G}\right)$ were synthesized by a newly developed sonochemical process [56] under argon atmosphere using titanium chloride $\left(\mathrm{TiCl}_{4}\right.$, 99.9\%, Aladdin), lithium hydride ( $\mathrm{LiH}, 99.4 \%$, Alfa Aesar), and graphene (97\%, Aladdin) as the raw materials. In a typical procedure, $\mathrm{TiCl}_{4}(2 \mathrm{mmol}), \mathrm{LiH}(8 \mathrm{mmol})$, and graphene $(20 \mathrm{mg})$ were sequentially added to $70 \mathrm{~mL}$ THF in a flask-3neck which was irradiated by ultrasonic waves $(40 \mathrm{kHz}, \mathrm{W}$ 600D, Shanghai Ultrasonic Instrument, Shanghai, China) for $4 \mathrm{~h}$ under mechanical stirring. A black precipitate of NP-TiH $\mathrm{H}_{2} @ \mathrm{G}$ was separated from the THF solution by filtration, washed twice with THF and finally dried at $70^{\circ} \mathrm{C}$ under dynamic vacuum. The obtained $\mathrm{NP}-\mathrm{TiH}_{2} @ \mathrm{G}$ was mixed with $\mathrm{NaAlH}_{4}$ on a planetary ball mill (Nanjing, China). The ball milling was conducted at $500 \mathrm{rpm}$ for $24 \mathrm{~h}$ in the milling jar filled with $50 \mathrm{~atm} \mathrm{H}_{2}$ at the ball-to-sample weight ratio of approximately $120: 1$. The doping amounts of NP$\mathrm{TiH}_{2} @ \mathrm{G}$ were set to be $x=0,1,3,5,7$, and $9 \mathrm{wt} \%$.

4.2. Characterization. The structure information was collected on a MiniFlex 600 X-ray diffractometer (XRD) (Rigaku, Japan) with $\mathrm{Cu} \mathrm{K}_{\alpha}$ radiation $(\lambda=0.15406 \mathrm{~nm})$ operated at $40 \mathrm{kV}$ and $15 \mathrm{~mA}$. The $2 \theta$ range was set at 10 $90^{\circ}$ with a $0.05^{\circ}$ step increment. A custom-designed container with a window covered by Scotch tape was used to prevent air and moisture exposure of the sample. The sample morphology and microstructure were observed with scanning electron microscope (SEM) (Hitachi S-4800), aberration-corrected scanning transmission electron microscope (STEM) (Titan $\mathrm{G}^{2}$ 80-200 Chemi STEM FEI, $200 \mathrm{kV}$ ), and TEM (Tecnai G ${ }^{2}$ F20 S-TWIN FEI, $200 \mathrm{kV}$ ). For SEM observation, the sample was transferred quickly to the SEM facility under Ar protection. For STEM and TEM examinations, the sample was protected with a double-tilt vacuum transfer holder (Gatan 648, USA). Atomic force microscope (AFM) characterization was performed on Bruker Dimension Icon under the tapping mode, with samples prepared by dropping freshly diluted sample solutions onto silicon substrates. X-ray photoelectron spectroscopy (XPS) analyses were carried out using a Thermo Scientific ESCALAB 250Xi spectrometer with a monochromatic Al Ka X-ray source at a base pressure of $6.8 \times 10^{-9}$ Torr. The Ti content of samples were determined by inductively coupled plasma (ICP) spectroscopy on a PE Optima 8000 instrument.

4.3. Property Measurements. A home-built temperature programmed desorption (TPD) system attached to a mass spectrometer (MS) was employed to characterize the temperature-dependent dehydrogenation behavior using $\mathrm{Ar}$ 


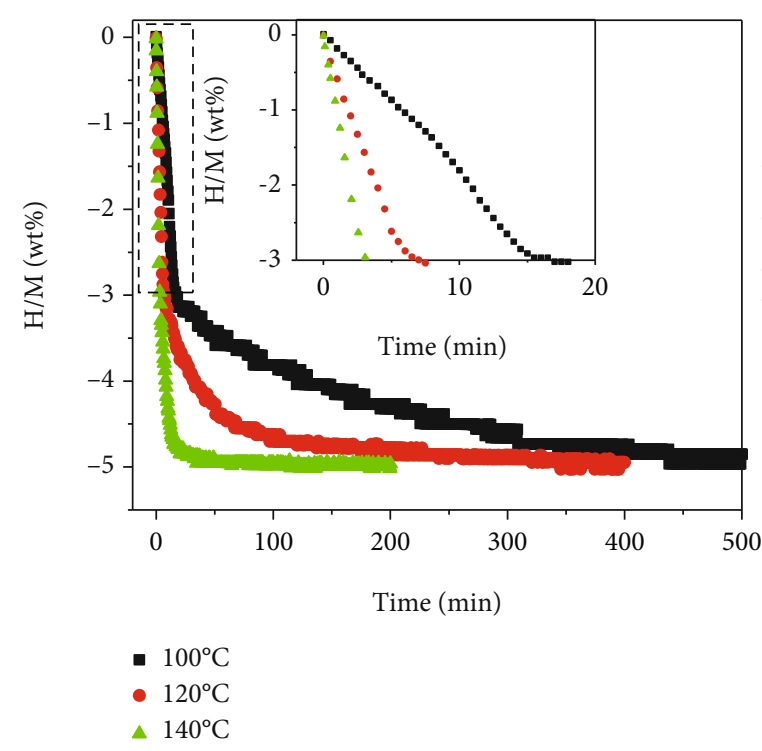

(a)

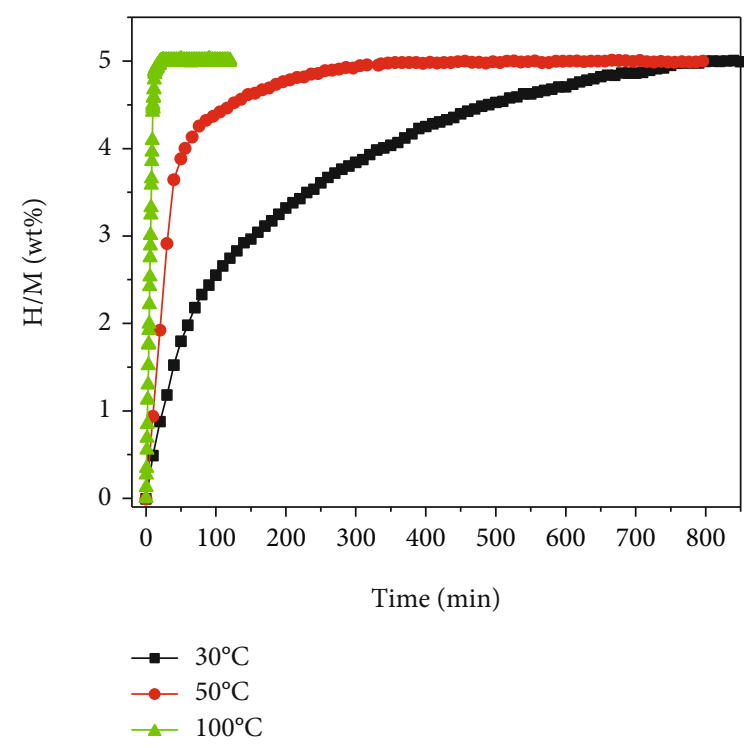

(c)

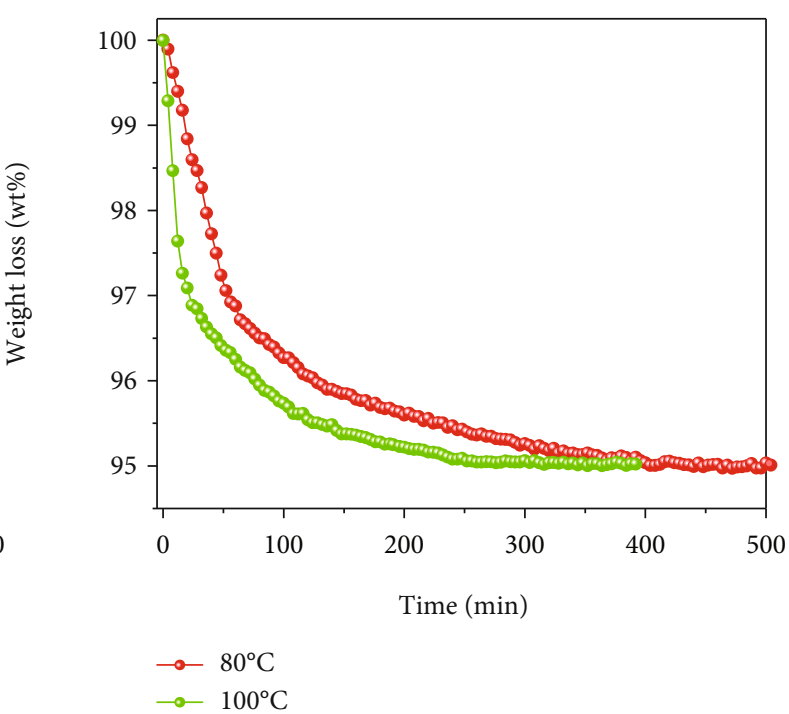

(b)

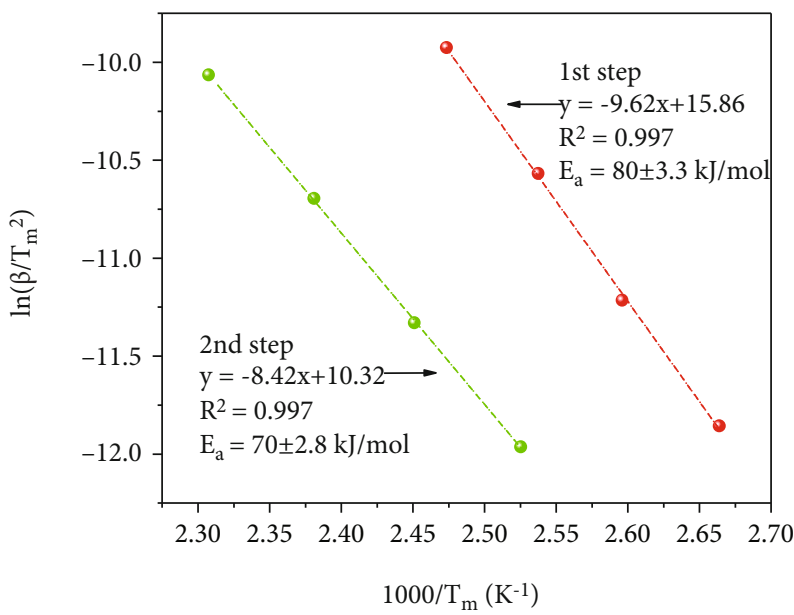

(d)

FIgURE 8: (a) Isothermal dehydrogenation curves, (b) isothermal TG curves, (c) isothermal hydrogenation curves, and (d) Kissinger's plots of activated $\mathrm{NaAlH}_{4}-7$ wt\% NP-TiH $@$ @G sample.

as a carrier gas with a flow rate of $20 \mathrm{~mL} \mathrm{~min}^{-1}$. For each test, approximately $40 \mathrm{mg}$ sample was heated up from room temperature to desired temperatures at $2^{\circ} \mathrm{C} \mathrm{min}^{-1}$. Quantitative dehydrogenation/hydrogenation properties were measured using a Sieverts-type apparatus under isothermal and nonisothermal conditions, and the sample loading was approximately $70 \mathrm{mg}$ sample. The nonisothermal data were acquired by gradually heating the sample from room temperature to a preset temperature at an average rate of $2^{\circ} \mathrm{C} \mathrm{min}^{-1}$ under primary vacuum $\left(-10^{-3}\right.$ Torr $)$ for dehydrogenation and $1^{\circ} \mathrm{C} \mathrm{min}^{-1}$ with 100 atm $\mathrm{H}_{2}$ for hydrogenation. The isothermal measurements were conducted by rapidly heating the sample to a desired temperature and then dwelling during the entire test. The temperature and pressure were monitored and recorded simultaneously, and the amounts of hydrogen released/uptaken were calculated based upon the ideal gas law. Thermogravimetric analysis (TGA) was carried out on a Netzsch TG 209 F3 instrument under an argon atmosphere at a ramping rate of $2^{\circ} \mathrm{C} \mathrm{min}{ }^{-1}$. Differential scanning calorimetry (DSC) experiments were performed with a NETZSCH DSC $200 \mathrm{~F} 3$ unit at $2^{\circ} \mathrm{C} \mathrm{min}{ }^{-1}$ of heating rate. Approximately $2 \mathrm{mg}$ of sample was placed in an $\mathrm{Al}_{2} \mathrm{O}_{3}$ crucible for measurement.

4.4. Theoretical Calculation. Density functional theory (DFT) calculations were conducted in the Vienna Ab initio Simulation Package (VASP). The generalized gradient approximation (GGA) with Perdew-Burke-Ernzerhof (PBE) 


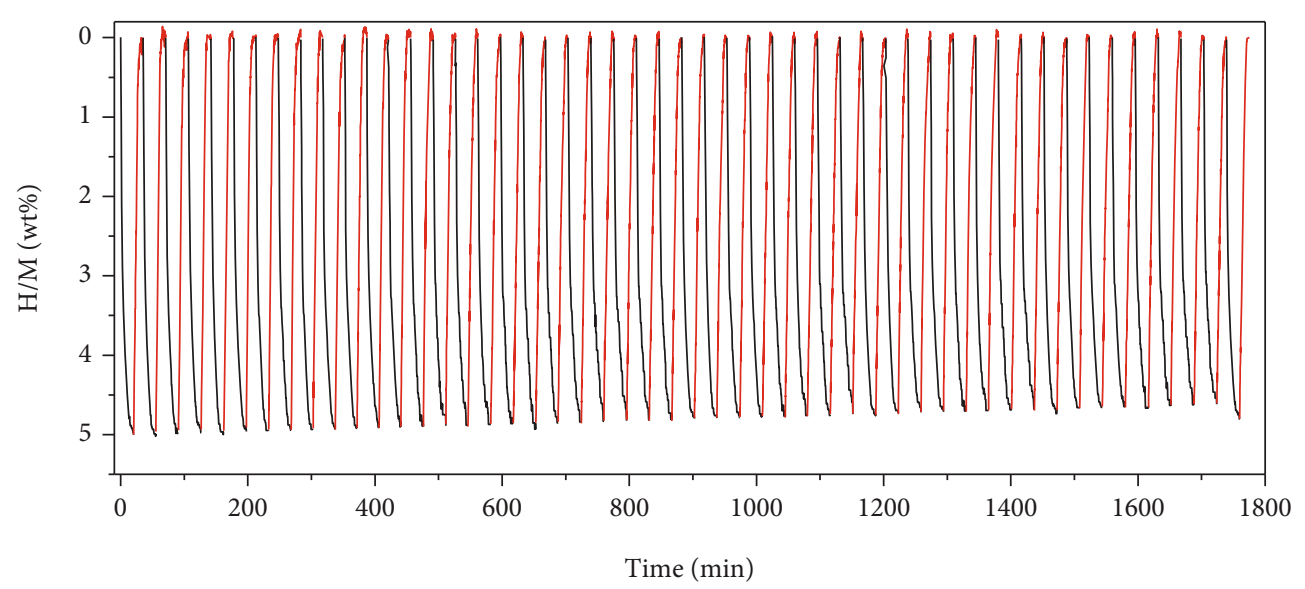

- Dehydrogenation

- Hydrogenation

(a)

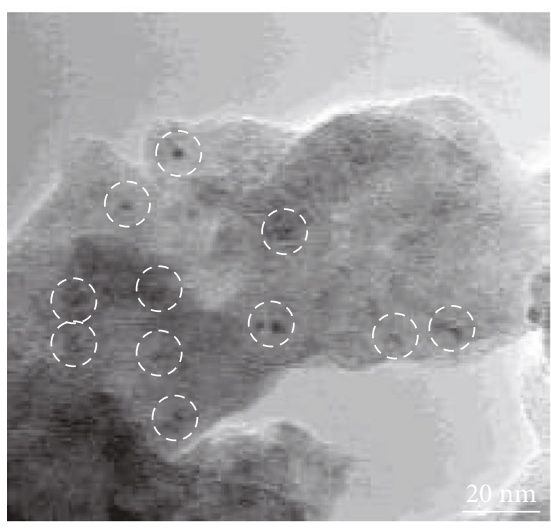

(b)
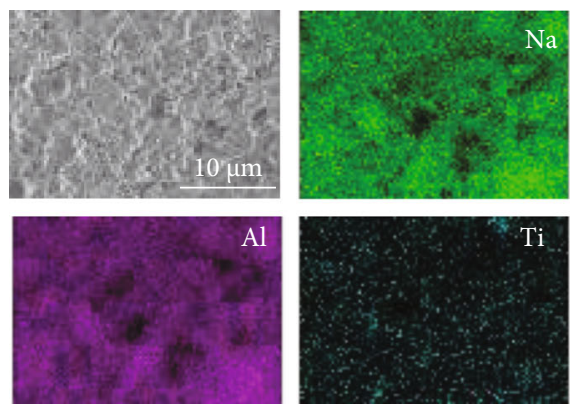

(d)
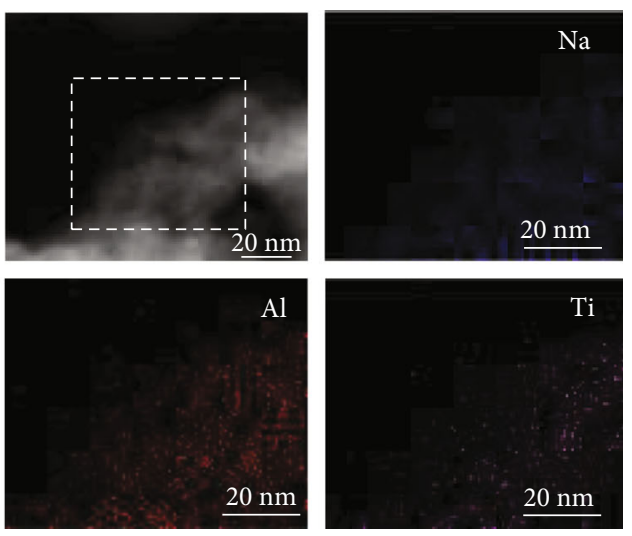

(c)

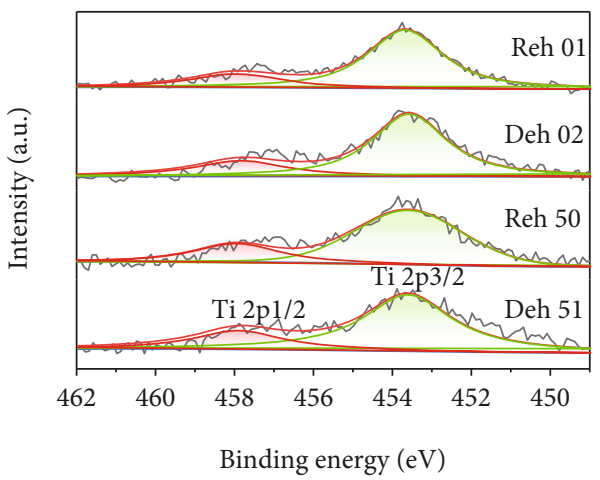

(e)

Figure 9: (a) Cycling tests operated at $140^{\circ} \mathrm{C}$ for dehydrogenation and $100^{\circ} \mathrm{C} / 100$ atm $\mathrm{H}_{2}$ for hydrogenation of $\mathrm{NaAlH}_{4}-7 \mathrm{wt} \% \mathrm{NP}-\mathrm{TiH} \mathrm{H}_{2} @ \mathrm{G}$, (b) TEM image, (c) STEM and corresponding EDS mapping images, (d) SEM and corresponding images, and (e) Ti $2 p$ XPS spectra of $\mathrm{NaAlH}_{4}-7$ wt\% NP-TiH $@$ @ sample after 50 cycles.

model was taken as the exchange-correlation functional [57]. Projector augmented wave pseudopotentials (PAWs) were employed to model the ionic potentials [58]. The precession setting of "PREC $=$ Accurate" was used. All atoms were fully relaxed until the force on them was less than $0.05 \mathrm{eV}^{-1}$. The Brillouin zone integration was performed with gammacentred sampling of $3 \times 3 \times 1$. The minimum-energy pathway was computed using the climbing-image nudged elastic 
band (CI-NEB) method [59]. Al(111) surface was selected because it has the lowest surface free energy and then is most likely exposed. A six-layer slab containing 96 atoms was constructed to simulate the surface with the lowest two layers fixed to represent the bulk. The thickness of vacuum layer was set as $20 \AA$ to avoid interaction between neighbouring images.

\section{Data Availability}

The data used to support the findings of this study are included within the article and supplementary information files and/or may be requested from the authors.

\section{Conflicts of Interest}

The authors declare no competing financial interest.

\section{Authors' Contributions}

Z.H.R. and X.Z. contributed equally to this work.

\section{Acknowledgments}

We gratefully acknowledge the financial support received from the Natural Science Foundation of Zhejiang Province (LD21E010002), the National Outstanding Youth Foundation of China (52125104), the National Natural Science Foundation of China (52071285 and 52001277), the National Key R\&D Program of China (2018YFB1502102), the Fundamental Research Funds for the Central Universities (2021FZZX001-09), and the National Youth TopNotch Talent Support Program.

\section{Supplementary Materials}

Figure S1: Raman spectrum of as-prepared solid product after sonochemical reaction between $\mathrm{TiCl}_{4}$ and $\mathrm{LiH}$ in THF. Figure S2: MS signal of gaseous product of reaction of $\mathrm{TiCl}_{4}$ with $\mathrm{LiH}$ in $\mathrm{THF}$ under ultrasonic treatment. Figure S3: XRD profile of the solid obtained by drying the filtrate of reaction of $\mathrm{TiCl}_{4}$ with $\mathrm{LiH}$ in THF under ultrasonic treatment. Figure S4: TEM image of pristine graphene. Figure S5: SEM image of $\mathrm{TiH}_{2}$ prepared by sonochemical reaction of $\mathrm{TiCl}_{4}$ and $\mathrm{LiH}$ without graphene as support. Figure S6: XRD profiles of $\mathrm{NaAlH}_{4}$ doped by 7 wt\% NF-TiH $\mathrm{N}_{2} @ \mathrm{G}$ prepared by different ultrasonic times. Figure S7: SEM image of commercial $\mathrm{TiH}_{2}$. Figure S8: Ti 2p XPS spectra of $\mathrm{NaAlH}_{4}$ mixed with commercial $\mathrm{TiH}_{2}$ and $\mathrm{TiH}_{2}$ nanoplates. Figure S9: XRD profiles of 7 wt $\%$ NF-TiH ${ }_{2} @ G$-containing $\mathrm{NaAlH}_{4}$ after different treatments. Figure S10: the volumetric dehydrogenation curves of activated NaAlH4-7 wt\% NPTiH2@G sample. Figure S11: XRD profiles of $\mathrm{NaAlH}_{4}^{-}$ 7 wt\% NP-TiH $2 @ G$ sample after ball milling and 1st de/ rehydrogenation cycle $\left(2 \theta: 39-44^{\circ}\right)$. Figure S12: energy barriers of $\mathrm{H}$ atom transferring from $\mathrm{NaAlH}_{4}$ molecule to $\mathrm{Al}$ surface (a) and single-Ti-substituted $\mathrm{Al}$ surface (b) and relaxed geometry of $\mathrm{NaAlH}_{4}$ molecule placed on two-Tisubstituted Al surface (c). Figure S13: TPD curves of activated $\mathrm{NaAlH}_{4}-7$ wt\% NP-TiH $\mathrm{N}_{2} @ \mathrm{G}$ sample with different heating rates. Figure S14: DSC curves of pristine $\mathrm{NaAlH}_{4}$ and $\mathrm{NaAlH}_{4}-7$ wt\% NP-TiH $\mathrm{N}_{2} @ \mathrm{G}$ samples. Table S1: comparison of activation energy (Ea) of $\mathrm{NaAlH}_{4}$ doped with different catalysts. (Supplementary Materials)

\section{References}

[1] L. Schlapbach and A. Züttel, "Hydrogen-storage materials for mobile applications," Nature, vol. 414, no. 6861, pp. 353358, 2001.

[2] J. Zheng, C.-G. Wang, H. Zhou et al., "Current research trends and perspectives on solid-state nanomaterials in hydrogen storage," Research, vol. 2021, article 3750689, 39 pages, 2021.

[3] C. G. Lang, Y. Jia, and X. Yao, "Recent advances in liquidphase chemical hydrogen storage," Energy Storage Materials, vol. 26, pp. 290-312, 2020.

[4] T. He, P. Pachfule, H. Wu, Q. Xu, and P. Chen, "Hydrogen carriers," Nature Reviews Materials, vol. 1, no. 12, article 16067, 2016.

[5] S.-I. Orimo, Y. Nakamori, J. R. Eliseo, A. Züttel, and C. M. Jensen, "Complex hydrides for hydrogen storage," Chemical Reviews, vol. 107, no. 10, pp. 4111-4132, 2007.

[6] L. Z. Ouyang, K. Chen, J. Jiang, X. S. Yang, and M. Zhu, "Hydrogen storage in light-metal based systems: a review," Journal of Alloys and Compounds, vol. 829, article 154597, 2020.

[7] L. Li, Y. Huang, C. An, and Y. Wang, "Lightweight hydrides nanocomposites for hydrogen storage: challenges, progress and prospects," Science China Materials, vol. 62, no. 11, pp. 1597-1625, 2019.

[8] X. B. Yu, Z. Tang, D. Sun, L. Ouyang, and M. Zhu, "Recent advances and remaining challenges of nanostructured materials for hydrogen storage applications," Progress in Materials Science, vol. 88, pp. 1-48, 2017.

[9] T. J. Frankcombe, "Proposed mechanisms for the catalytic activity of Ti in $\mathrm{NaAlH}_{4}$," Chemical Reviews, vol. 112, no. 4, pp. 2164-2178, 2012.

[10] B. Bogdanović, M. Felderhoff, A. Pommerin, F. Schüth, and N. Spielkamp, "Advanced hydrogen-storage materials based on Sc-, Ce-, and Pr-doped $\mathrm{NaAlH}_{4}$," Advanced Materials, vol. 18, no. 9, pp. 1198-1201, 2006.

[11] N. A. Ali and M. Ismail, "Modification of $\mathrm{NaAlH}_{4}$ properties using catalysts for solid-state hydrogen storage: a review," International Journal of Hydrogen Energy, vol. 46, no. 1, pp. 766-782, 2021.

[12] Y. F. Liu, Z. H. Ren, X. Zhang et al., "Development of catalystenhanced sodium alanate as an advanced hydrogen-storage material for mobile applications," Energy Technology, vol. 6, no. 3, pp. 487-500, 2018.

[13] X. L. Zhang, Y. F. Liu, X. Zhang, J. J. Hu, M. X. Gao, and H. G. Pan, "Empowering hydrogen storage performance of $\mathrm{MgH}_{2}$ by nanoengineering and nanocatalysis," Materials Today Nano, vol. 9, article 100064, 2020.

[14] W. X. Zhang, X. Zhang, Z. G. Huang et al., "Recent development of lithium borohydride-based materials for hydrogen storage," Advanced Energy and Sustainability Research, vol. 2, no. 10, article 2100073, 2021.

[15] B. Bogdanović and M. Schwickardi, "Ti-doped alkali metal aluminium hydrides as potential novel reversible hydrogen 
storage materials ${ }^{1}, "$ Journal of Alloys and Compounds, vol. 253-254, pp. 1-9, 1997.

[16] G. Lee, J. Shim, Y. Cho, and K. Lee, "Improvement in desorption kinetics of $\mathrm{NaAlH}_{4}$ catalyzed with $\mathrm{TiO}_{2}$ nanopowder," International Journal of Hydrogen Energy, vol. 33, no. 14, pp. 3748-3753, 2008.

[17] N. Eigen, M. Kunowsky, T. Klassen, and R. Bormann, "Synthesis of $\mathrm{NaAlH}_{4}$-based hydrogen storage material using milling under low pressure hydrogen atmosphere," Journal of Alloys and Compounds, vol. 430, no. 1-2, pp. 350-355, 2007.

[18] X. Z. Xiao, K. R. Yu, X. L. Fan et al., "Synthesis and hydriding/ dehydriding properties of nanosized sodium alanates prepared by reactive ball-milling," International Journal of Hydrogen Energy, vol. 36, no. 1, pp. 539-548, 2011.

[19] G. D. Zou, B. Z. Liu, J. X. Guo, Q. Zhang, C. Fernandez, and Q. Peng, "Synthesis of nanoflower-shaped Mxene derivative with unexpected catalytic activity for dehydrogenation of sodium alanates," ACS Applied Materials \& Interfaces, vol. 9, no. 8, pp. 7611-7618, 2017.

[20] X. Z. Xiao, X. L. Fan, K. R. Yu et al., "Catalytic mechanism of new TiC-doped sodium alanate for hydrogen storage," Journal of Physical Chemistry C, vol. 113, no. 48, pp. 20745-20751, 2009.

[21] Z. L. Yuan, D. F. Zhang, G. X. Fan, Y. Chen, Y. Fan, and B. Liu, "Synergistic effect of $\mathrm{CeF}_{3}$ Nanoparticles supported on $\mathrm{Ti}_{3} \mathrm{C}_{2}$ MXene for catalyzing hydrogen storage of $\mathrm{NaAlH}_{4}$," $A C S$ Applied Energy Materials, vol. 4, no. 3, pp. 2820-2827, 2021.

[22] R. C. Jiang, X. Xiao, J. Zheng, M. Chen, and L. Chen, "Remarkable hydrogen absorption/desorption behaviors and mechanism of sodium alanates in-situ doped with Ti-based 2D Mxene," Materials Chemistry and Physics, vol. 242, article 122529, 2020.

[23] J. W. Kim, J.-H. Shim, S. C. Kim et al., "Catalytic effect of titanium nitride nanopowder on hydrogen desorption properties of $\mathrm{NaAlH}_{4}$ and its stability in $\mathrm{NaAlH}_{4}$," Journal of Power Sources, vol. 192, no. 2, pp. 582-587, 2009.

[24] L. Li, F. Qiu, Y. Wang et al., "Tin catalyst for the reversible hydrogen storage performance of sodium alanate system," Journal of Materials Chemistry, vol. 22, no. 27, p. 13782, 2012.

[25] L. Li, F. Y. Qiu, Y. J. Wang et al., "Crystalline $\mathrm{TiB}_{2}$ : an efficient catalyst for synthesis and hydrogen desorption/absorption performances of $\mathrm{NaAlH}_{4}$ system," Journal of Materials Chemistry, vol. 22, no. 7, pp. 3127-3132, 2012.

[26] X. Xiao, L. Chen, X. Wang, S. Li, C. Chen, and Q. Wang, "Reversible hydrogen storage properties and favorable codoping mechanism of the metallic Ti and $\mathrm{Zr}$ co-doped sodium aluminum hydride," International Journal of Hydrogen Energy, vol. 33, no. 1, pp. 64-73, 2008.

[27] P. Wang and C. M. Jensen, "Preparation of Ti-doped sodium aluminum hydride from mechanical milling of $\mathrm{NaH} / \mathrm{Al}$ with off-the-shelf Ti powder," Journal of Physical Chemistry B, vol. 108, no. 40, pp. 15827-15829, 2004.

[28] M. P. Pitt, P. E. Vullum, M. H. Sørby et al., "Hydrogen absorption kinetics and structural features of $\mathrm{NaAlH}_{4}$ enhanced with transition-metal and Ti-based nanoparticles," International Journal of Hydrogen Energy, vol. 37, no. 20, pp. 1517515186, 2012.

[29] X. Zhang, X. L. Zhang, Z. H. Ren et al., “Amorphous-carbonsupported ultrasmall $\mathrm{TiB}_{2}$ nanoparticles with high catalytic activity for reversible hydrogen storage in $\mathrm{NaAlH}_{4}$," Frontiers in Chemistry, vol. 8, article 419, 2020.
[30] X. Zhang, Z. H. Ren, Y. H. Lu et al., "Facile synthesis and superior catalytic activity of nano-TiN@N-C for hydrogen storage in $\mathrm{NaAlH}_{4}$," ACS Applied Materials \& Interfaces, vol. 10, no. 18, pp. 15767-15777, 2018.

[31] R. Y. Wu, H. du, Z. Y. Wang, M. Gao, H. Pan, and Y. Liu, "Remarkably improved hydrogen storage properties of $\mathrm{NaAlH}_{4}$ doped with 2D titanium carbide," Journal of Power Sources, vol. 327, pp. 519-525, 2016.

[32] F. Schüth, B. Bogdanović, and M. Felderhoff, "Light metal hydrides and complex hydrides for hydrogen storage," Chemical Communications, vol. 20, pp. 2249-2258, 2004.

[33] S. Zhang, C. Lu, N. Takeichi, T. Kiyobayashi, and N. Kuriyama, "Reaction stoichiometry between $\mathrm{TiCl}_{3}$ and $\mathrm{NaAlH}_{4}$ in Ti-doped alanate for hydrogen storage: the fate of the titanium species," International Journal of Hydrogen Energy, vol. 36, no. 1, pp. 634-638, 2011.

[34] A. Léon, D. Schild, and M. Fichtner, "Chemical state of Ti in sodium alanate doped with $\mathrm{TiCl}_{3}$ using X-ray photoelectron spectroscopy," Journal of Alloys and Compounds, vol. 404406, pp. 766-770, 2005.

[35] P. Wang, X. D. Kang, and H. M. Cheng, "Improved hydrogen storage of TiF3-Doped $\mathrm{NaAlH}_{4}$," ChemPhysChem, vol. 6, no. 12, pp. 2488-2491, 2005.

[36] L. Li, F. Y. Qiu, Y. J. Wang et al., "Improved dehydrogenation performances of $\mathrm{TiB}_{2}$-doped sodium alanate," Materials Chemistry and Physics, vol. 134, no. 2-3, pp. 1197-1202, 2012.

[37] T. Wang, J. Wang, A. D. Ebner, and J. A. Ritter, "Reversible hydrogen storage properties of $\mathrm{NaAlH}_{4}$ catalyzed with scandium," Journal of Alloys and Compounds, vol. 450, no. 1-2, pp. 293-300, 2008.

[38] K. J. Gross, E. H. Majzoub, and S. W. Spangler, "The effects of titanium precursors on hydriding properties of alanates," Journal of Alloys and Compounds, vol. 356-357, pp. 423-428, 2003.

[39] X. Kang, P. Wang, and H. Cheng, "In situ formation of Ti hydride and its catalytic effect in doped $\mathrm{NaAlH}_{4}$ prepared by milling $\mathrm{NaH} / \mathrm{Al}$ with metallic $\mathrm{Ti}$ powder," International Journal of Hydrogen Energy, vol. 32, no. 14, pp. 29432948, 2007.

[40] X. Zhang, Y. Liu, K. Wang, M. Gao, and H. Pan, "Remarkably improved hydrogen storage properties of nanocrystalline $\mathrm{TiO}_{2}$-modified $\mathrm{NaAlH}_{4}$ and evolution of Ti-containing species during dehydrogenation/hydrogenation," Nano Research, vol. 8, no. 2, pp. 533-545, 2015.

[41] G. K. P. Dathara and D. S. Mainardi, "Structure and dynamics of Ti-Al-H compounds in Ti-doped $\mathrm{NaAlH}_{4}$," Molecular Simulation, vol. 34, no. 2, pp. 201-210, 2008.

[42] G. K. P. Dathar and D. S. Mainardi, "Kinetics of hydrogen desorption in $\mathrm{NaAlH}_{4}$ and Ti-containing $\mathrm{NaAlH}_{4}$," Journal of Physical Chemistry C, vol. 114, no. 17, pp. 8026-8031, 2010.

[43] J. Íniguez and T. Yildirim, "First-principles study of Ti-doped sodium alanate surfaces," Applied Physics Letters, vol. 86, no. 10, article 103109, 2005.

[44] Z. H. Ren, X. Zhang, Z. G. Huang et al., "Controllable synthesis of $2 \mathrm{D} \mathrm{TiH}_{2}$ nanoflakes with superior catalytic activity for lowtemperature hydrogen cycling of $\mathrm{NaAlH}_{4}$," Chemical Engineering Journal, vol. 427, article 131546, 2022.

[45] X. Zhang, Z. H. Ren, X. L. Zhang, M. Gao, H. Pan, and Y. Liu, "Triggering highly stable catalytic activity of metallic titanium for hydrogen storage in $\mathrm{NaAlH}_{4}$ by preparing ultrafine nanoparticles," Journal of Materials Chemistry A, vol. 7, no. 9, pp. 4651-4659, 2019. 
[46] US Department of Energy, "DOE Technical Targets for Onboard Hydrogen Storage for Light-Duty Vehicles," US Washington DC, 2016https://www.energy.gov/eere/fuelcells/ doe-technical-targets-onboard-hydrogen-storage-light-dutyvehicles.

[47] X. Zhang, R. Y. Wu, Z. Y. Wang, M. Gao, H. Pan, and Y. Liu, "Preparation and catalytic activity of a novel nanocrystalline $\mathrm{ZrO}_{2} @ \mathrm{C}$ composite for hydrogen storage in $\mathrm{NaAlH}_{4}$," Chemistry-An Asian Journal, vol. 11, no. 24, pp. 3541-3549, 2016.

[48] Y. F. Liu, C. Liang, H. Zhou, M. Gao, H. Pan, and Q. Wang, “A novel catalyst precursor $\mathrm{K}_{2} \mathrm{TiF}_{6}$ with remarkable synergetic effects of $\mathrm{K}$, Ti and $\mathrm{F}$ together on reversible hydrogen storage of $\mathrm{NaAlH}_{4}$," Chemical Communications, vol. 47, no. 6, pp. 1740-1742, 2011.

[49] L. Li, Y. Wang, F. Y. Qiu et al., "Reversible hydrogen storage properties of $\mathrm{NaAlH}_{4}$ enhanced with TiN catalyst," Journal of Alloys and Compounds, vol. 566, pp. 137-141, 2013.

[50] N. H. Idris, A. S. K. Anuar, N. A. Ali, and M. Ismail, "Effect of $\mathrm{K}_{2} \mathrm{NbF}_{7}$ on the hydrogen release behaviour of $\mathrm{NaAlH}_{4}$," Journal of Alloys and Compounds, vol. 851, article 156686, 2021.

[51] J. F. Mao, Z. Guo, and H. Liu, "Improved hydrogen sorption performance of $\mathrm{NbF}_{5}$-catalysed $\mathrm{NaAlH}_{4}$," International Journal of Hydrogen Energy, vol. 36, no. 22, pp. 14503-14511, 2011.

[52] N. S. Mustafa, M. S. Yahya, N. Sazelee, N. A. Ali, and M. Ismail, "Dehydrogenation properties and catalytic mechanism of the $\mathrm{K}_{2} \mathrm{NiF}_{6}$-doped $\mathrm{NaAlH}_{4}$ System," ACS Omega, vol. 3, no. 12, pp. 17100-17107, 2018.

[53] N. Sazelee, N. S. Mustafa, M. S. Yahya, and M. Ismail, "Enhanced dehydrogenation performance of $\mathrm{NaAlH}_{4}$ by the addition of spherical SrTiO3," International Journal of Energy Research, vol. 45, no. 6, pp. 8648-8658, 2021.

[54] X. L. Fan, X. Z. Xiao, L. X. Chen et al., "Hydriding-dehydriding kinetics and the microstructure of La- and Sm-doped $\mathrm{NaAlH}_{4}$ prepared via direct synthesis method," International Journal of Hydrogen Energy, vol. 36, no. 17, pp. 10861-10869, 2011.

[55] D. E. Mencer, T. R. Hess, T. Mebrahtu, D. L. Cocke, and D. G. Naugle, "Surface reactivity of titanium-aluminum alloys: $\mathrm{Ti}_{3} \mathrm{Al}$, TiAl, and $\mathrm{TiAl}_{3}$," Journal of Vacuum Science \& Technology A: Vacuum, Surfaces, and Films, vol. 9, no. 3, pp. 1610$1615,1991$.

[56] X. Zhang, Y. F. Liu, Z. H. Ren et al., "Realizing 6.7 wt\% reversible storage of hydrogen at ambient temperature with nonconfined ultrafine magnesium hydrides," Energy \& Environmental Science, vol. 14, no. 4, pp. 2302-2313, 2021.

[57] J. P. Perdew, K. Burke, and M. Ernzerhof, "Generalized gradient approximation made simple," Physical Review Letters, vol. 77, no. 18, pp. 3865-3868, 1996.

[58] P. E. Blöchl, "Projector augmented-wave method," Physical Review B, vol. 50, no. 24, pp. 17953-17979, 1994.

[59] G. Henkelman, B. P. Uberuaga, and H. Jónsson, “A climbing image nudged elastic band method for finding saddle points and minimum energy paths," Journal of Chemical Physics, vol. 113, no. 22, pp. 9901-9904, 2000. 